\title{
Mechanisms of Aging and Liver Functions
}

\author{
Nicoletta Gagliano ${ }^{\text {a }}$ Fabio Grizzi $^{\text {b Giorgio Annoni }}{ }^{c, d}$ \\ ${ }^{a}$ Department of Human Morphology, University of Milan, Milan; ${ }^{b}$ Laboratories of Quantitative Medicine, \\ Istituto Clinico Humanitas IRCCS, Rozzano; ' Chair of Geriatrics and School of Specialization in Geriatrics, \\ University of Milan-Bicocca, Milan; ${ }^{d}$ S. Gerardo Hospital, Monza, Italy
}

\section{Key Words}

Aged liver, stress response $\cdot$ Aging liver $\cdot$ Liver

regeneration $\cdot$ Mast cells

\begin{abstract}
Background/Aims: Morphofunctional studies suggest that the liver, compared with other organs, ages fairly well. Its success is ascribable to its lasting ability to regenerate, even if the potential of the cells to replicate progressively declines with age. The aim of this study was to analyze some aspects of the early phases of liver regeneration, its capacity to mount a stress response, and the inflammatory response in the early stage of an acute injury. Methods: Rats aged 2, 6, 12 and 19 months received a single intraperitoneal injection of $\mathrm{CCl}_{4}$, and morphological, biochemical and molecular evaluations were done 2 and 24 h later. Results: AST and ALT, starting at age 12 months, were significantly higher than in the younger rats after $\mathrm{CCl}_{4}$. Histological modifications were already detectable after $2 \mathrm{~h}$ in rats aged 12 and 19 months, thereafter becoming more diffuse and marked, whereas they become evident only $24 \mathrm{~h}$ after the intoxication in rats aged 2 and 6 months. Albumin, c-fos, c-myc, hepatocyte growth factor, transforming growth factor- $\alpha$ and HSP70 mRNA levels decreased $24 \mathrm{~h}$ after $\mathrm{CCl}_{4}$ starting at age 12 months. Mast cell density was higher in the young rats than the old ones. Conclusion: Our results point to: (a) a basically
\end{abstract}

preserved regenerative response of the aged liver, although somehow weaker and slower, with reduced ability to counteract agents inducing cell necrosis; (b) a decrease in the HSP70 response suggesting a reduction in homeostatic capacity, and (c) a lower inflammatory response during aging.

Copyright $\odot 2007$ S. Karger AG, Basel

Aging affects organs, tissues and cell functions to different extents, resulting in a decline in the capacity of the whole organism to cope with its environment. Morphofunctional studies suggest that the liver, compared with other organs, ages fairly well [1].

This concept, for a long time more anecdotal than scientifically proven, was firmly demonstrated several years ago by means of a rat transplant model [2]. Livers from young (5 months) and old (28 months) syngeneic BN/ BiRij rats were transplanted into young recipients, and there were no differences in the survival curves. Analysis of the transplanted aged livers showed reduced weight of the organ, hepatocyte degeneration, bile duct proliferation, pigment deposition, and mild to moderate fibrosis $[2,3]$. All these features were perhaps well known, but certainly not the unexpected ability of the liver to survive far beyond the rats' maximum life span [2]. More evidence comes from the finding that under physiological

\section{KARGER \\ Fax +41613061234 \\ E-Mail karger@karger.ch}

www.karger.com (c) 2007 S. Karger AG, Basel

$0257-2753 / 07 / 0252-0118 \$ 23.50 / 0$

Accessible online at:

www.karger.com/ddi
Prof. Giorgio Annoni

DIMEP, Building U8, Via Cadore 48

IT-20054 Monza (Italy)

Tel. +390392333 458, Fax +390392334358

E-Mail giorgio.annoni@unimib.it 
conditions the liver's overall functions do not appear seriously affected by aging, as suggested by a full analysis of serum tests in subjects of different ages [4]. However, wide interindividual variability is the main characteristic of aged people $[1,4]$.

The successful aging of the liver is probably ascribable to its relatively well-preserved ability to regenerate, even though the potential of the cells to replicate progressively declines with age [5]. This statement is based on the observation that partially resected livers in old animals need longer to regain their original volume, compared to the young. This can also be elicited experimentally by an acute chemical treatment with $\mathrm{CCl}_{4}[6-8]$, providing a useful model to investigate aspects such as: (a) the triggering mechanisms in the early phase of regeneration; (b) the capacity to mount a stress response to a noxious stimulus, and (c) the inflammatory response in the early phase of an acute injury.

Here we report and review these aspects in the in vivo model of a single intraperitoneal injection of $\mathrm{CCl}_{4}$ to young ( 2 months), adult (6 and 12 months) and aged rats (19 months). All the evaluations, biochemical, morphological and molecular, were done 2 and $24 \mathrm{~h}$ after liver intoxication, in comparison with age-matched untreated animals.

\section{Liver Regeneration}

Under physiological conditions the liver is a largely quiescent organ in terms of cell proliferation since only a very small percentage of hepatocytes undergoes mitosis at any given time. Cell necrosis or surgical resection induces the hepatocytes to proliferate and replicate, thus restoring the previous functional capacity as well as the original mass [9].

Cell death caused by $\mathrm{CCl}_{4}$ drives hepatocytes through two main steps: a 'priming' phase that gives them replicative competence, and a 'progression' phase in which primed cells undergo DNA replication [6, 9]. This transition requires the expression of some genes whose products regulate key events during the G0 and G1 phases. Among these early genes, $c$-fos and c-myc $[6,10]$ act as transcription factors, encoding nuclear phosphoproteins believed to function as regulators of cell proliferation.

Regeneration is strictly governed by growth factors and cytokines, as suggested in vitro and in vivo [11] and, in this context, up-regulation of hepatocyte growth factor (HGF) and transforming growth factor (TGF)- $\alpha$ exert a positive control $[6,10]$ acting, respectively, in an auto-

Pathophysiology of Aging Liver crine and paracrine fashion. The whole process ends once the liver mass reaches a species- and age-specific fraction of total body mass, indicating that negative regulatory influences are needed and, in fact, a stop signal is encoded by the TGF- $\beta_{1}$ gene [12] .

All this machinery in the senescent phenotype has been comprehensively investigated by analyzing serum transaminases, liver histology, GSH content, albumin, cfos, $c-m y c, H G F, T G F-\alpha$ and TGF- $\beta_{1}$ gene expression [13]. AST and ALT levels, biochemical markers of hepatic injury, are not affected by aging per se, but are significantly higher than in young rats after $\mathrm{CCl}_{4}$, starting at age 12 months and more in the oldest rats, since there is more cell necrosis.

The histological findings indicate a very similar morphological appearance in control rats, but treated rats have localized cell necrosis in the central region (zone 3) with an inflammatory reaction, the portal tracts being almost spared. Hydropic degeneration, with a clear cytoplasm, vacuolization or ballooning, and fatty changes from few droplets to diffuse involvement, are the main features in the pericentral zone (fig. 1). These findings are evident $24 \mathrm{~h}$ after the intoxication in rats aged 2 and 6 months, but are already detectable after $2 \mathrm{~h}$ in those aged 12 and 19 months, thereafter becoming more diffuse and marked. All this points to a lower capacity to counteract the free radical toxicity subsequent to $\mathrm{CCl}_{4}$ metabolism. The reduced GSH content of aged livers probably explains the susceptibility to oxidative stress $[13,14]$. However, the recent finding of changes in the sinusoidal endothelium and spaces of Disse, termed 'pseudocapillarization', that restrict the availability of oxygen and other substrates [15], also marks the lower energy status of the aged liver as a major determinant of impaired xenobiotic detoxification.

At the molecular level this model discloses several features of the aging process. In both young and aged animals there was a clear reduction of albumin gene transcription $24 \mathrm{~h}$ after $\mathrm{CCl}_{4}$ intoxication but, $2 \mathrm{~h}$ after the treatment, this was true only in the old rats, since this gene was up-regulated in the young ones, pointing to a more efficient transcription machinery $[13,16]$.

Analysis of the c-fos and c-myc gene offers information on the entry of the priming quiescent hepatocytes into the cell cycle and of the better ability of young and adult cells, compared to senescent one, $2 \mathrm{~h}$ after $\mathrm{CCl}_{4}$ (fig. 2a). The persistence of c-fos transcripts for $24 \mathrm{~h}$ only in 6-month-old rats might correspond to a second round of replication, because only hepatocytes of this age are able to replicate through more than one cell cycle 
Fig. 1. Microphotographs showing histological changes in liver tissue. Two-monthold control rat (a), or $2 \mathrm{~h}$ (b) and $24 \mathrm{~h}$ after $\mathrm{CCl}_{4}$ (c); 19-month-old controls (d), or $2 \mathrm{~h}$ (e) and $24 \mathrm{~h}$ after $\mathrm{CCl}_{4}$ (f). Sections were stained with hematoxylin and eosin. Orig. magnif. $\times 200$.
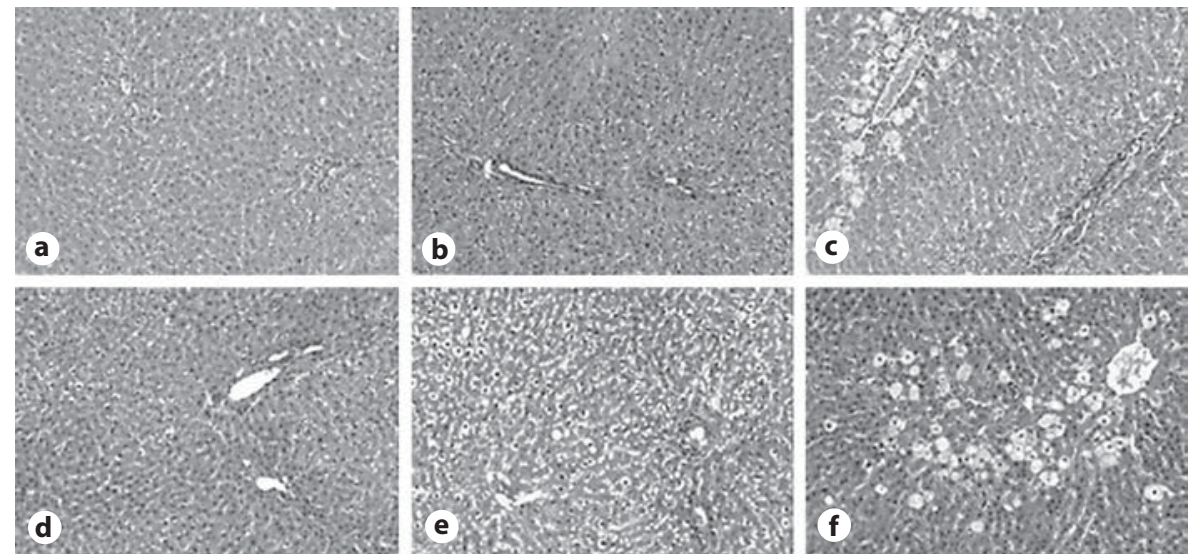

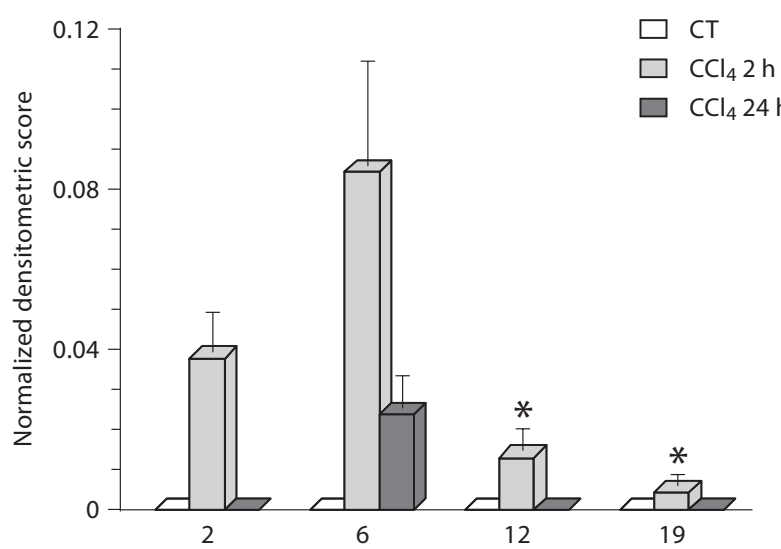

a

Months

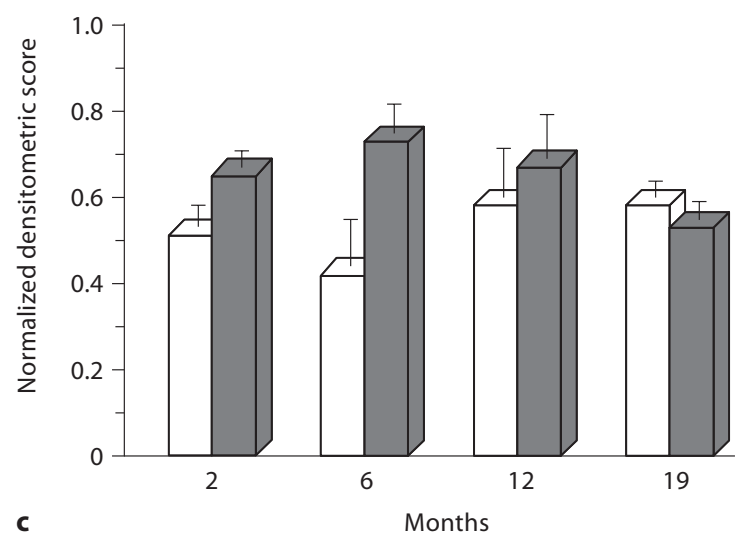

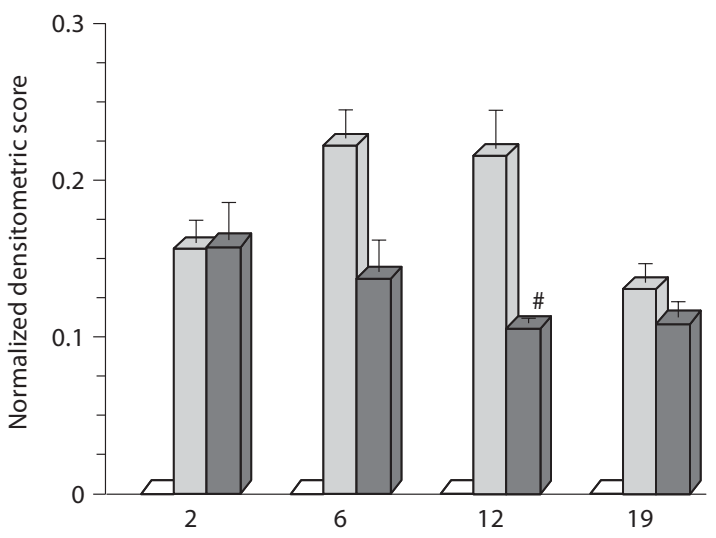

b

Months

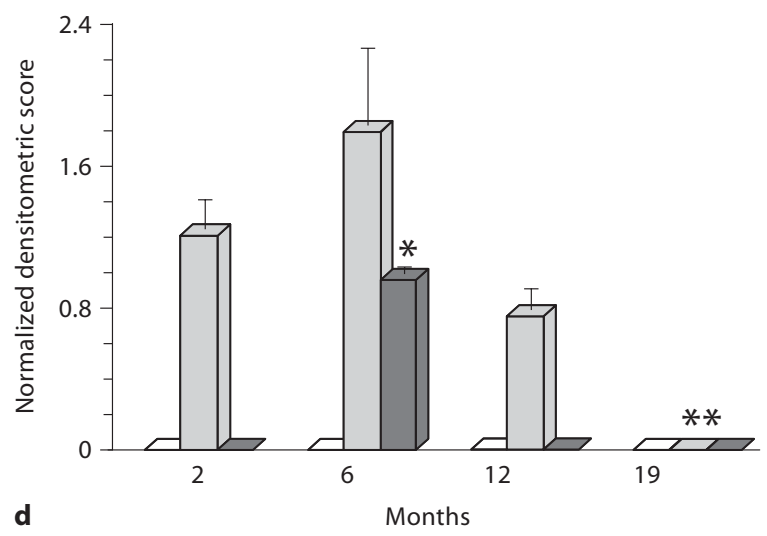

Fig. 2. Bar graph illustrating the mRNA steady-state levels in liver homogenates from control and treated rats aged 2, 6, 12 and 19 months. Changes in mRNA signal of c-fos (a), c-myc (b), TGF- $\alpha$ (c) and HSP70 (d) are expressed as optical densities normalized on GAPDH gene expression. Values are means \pm SEM (4 animals per age and treatment group). ${ }^{*} \mathrm{p}<0.05$ vs. 6 months old, $\mathrm{CCl}_{4} 2 \mathrm{~h}$; ${ }^{*} \mathrm{p}<0.05$ vs. 12 months old, $\mathrm{CCl}_{4} 2$ h; ** $\mathrm{p}<0.05$ vs. 2,6 and 12 months old, $\mathrm{CCl}_{4} 2 \mathrm{~h}$. 
[9]. At the same time, the fact that c-myc mRNA levels were highest in young-adult rodents (fig. 2b) suggests some facilitation of proliferation, either by enhancing the responsiveness of growth factors [17] or by shortening the cell cycle, accelerating the G0-G1 transition [18].

All together the c-fos and c-myc data show that senescent hepatocytes are triggered for a delayed, weaker regenerative response because they are blocked in G1 phase, as already demonstrated in fibroblasts [19].

In this experimental context, the HGF gene transcript was always more abundant in the old animals, possibly because of their more limited ability to maintain homeostasis, as suggested by a positive relationship between plasma HGF levels, hepatic necrosis and systemic inflammation $[20,21]$.

The involvement of TGF- $\alpha$ seems different from that of HGF: TGF- $\alpha$ mRNA levels were increased after $24 \mathrm{~h}$ in rats aged 2, 6, and 12 months, but not in the old animals (fig. 2c).

One of the most powerful stop signals to liver growth is exerted by TGF- $\beta_{1}$ [12]. Again, in this model, the tendency to a progressive age-dependent decrease of its transcripts suggests that the aged liver takes longer to complete regeneration, as also indicated by the longer cell proliferation phase after treatment with a neutralizing TGF- $\beta_{1}$ antibody [22].

\section{Stress Response of Aged Livers}

The heat-shock response is a highly conserved defense mechanism against noxious agents, including high temperature, alcohol, heavy metals, xenobiotics, oxidants, and radiation, and is mediated by the transient transcription of genes belonging to the family of heat-shock proteins (HSP) [23]. This provides a state of increased cell resistance, because HSP form transient complexes with other cellular proteins, promoting their folding into the correct secondary structures thus preventing denaturation.

As described by several authors [24-27], aging is associated with a decrease in HSP70 response, and this is assumed to be one of the main features of aging, which involves a reduction in homeostatic capacity. Therefore, it is not surprising that $2 \mathrm{~h}$ after $\mathrm{CCl}_{4}, \mathrm{HSP} 70 \mathrm{mRNA}$ levels were raised only in young-adult rats, and almost undetectable in the oldest ones (fig. $2 \mathrm{~d}$ ). Induction of the gene still persisted at $24 \mathrm{~h}$ only in the adult animals $(6$ months). The ability to produce the protective HSP70 is unbalanced with increasing age and thus may explain, at least in part, the increased susceptibility of aged livers to stress- and age-associated diseases. Furthermore, the knowledge of the highly integrated and complex responses of aged organisms to environmental stress will provide a basis for developing therapies related to aging-associated pathophysiological conditions.

\section{Inflammatory Response}

Inflammation involves a complex set of interactions among soluble factors and cells, and identifies a finelytuned local protective response, because its deficiencies or excesses may cause morbidity and shorten life span [28]. This response is modified in the elderly, where both function and phenotype of pivotal cells, i.e. monocytes and granulocytes, are affected [29].

Much attention has focused on the recruitment of leukocytes from the blood. However, a rapid response requires sentinel cells pre-stationed in the tissues, such as macrophages and mast cells (MC) [30]. MC are a heterogeneous family of cells containing different enzymatic proteins, such as tryptase, chymase, vasoactive amines, neutral proteases, carboxypeptidase and cathepsin E, whose content depends on the animal species and stage of development. MC maturation can be induced by a wide range of stimuli, including multivalent antigens (allergens), neuropeptides, growth factors, complement components (serum glycoproteins) and various drugs [3134]. Their activation results in degranulation, with secretion of preformed mediators stored in the cytoplasmic granules, synthesis of pro-inflammatory lipid mediators, and the synthesis and secretion of cytokines and chemokines [35]. All these events lead to both immediate and late-phase responses. Recently, Nguyen et al. [36] have suggested the ability of prostaglandin $\mathrm{E}_{2}\left(\mathrm{PGE}_{2}\right)$ to initiate $\mathrm{MC}$ degranulation changes in the aging animal, and therefore elevated $\mathrm{PGE}_{2}$ levels might provide an important pathway by which MCs are engaged in inflammatory responses in the elderly patient.

MCs are critical effectors in many pathological conditions, including acute liver injury and, since their tissue accumulation can change significantly in the course of the inflammatory response, they have been assigned a role as an early indicator of this process.

MCs have recently been studied to investigate their involvement in the mechanisms leading to age-related chronic diseases $[37,38]$. In the experimental model described, MCs were evaluated as a quantitative parameter 

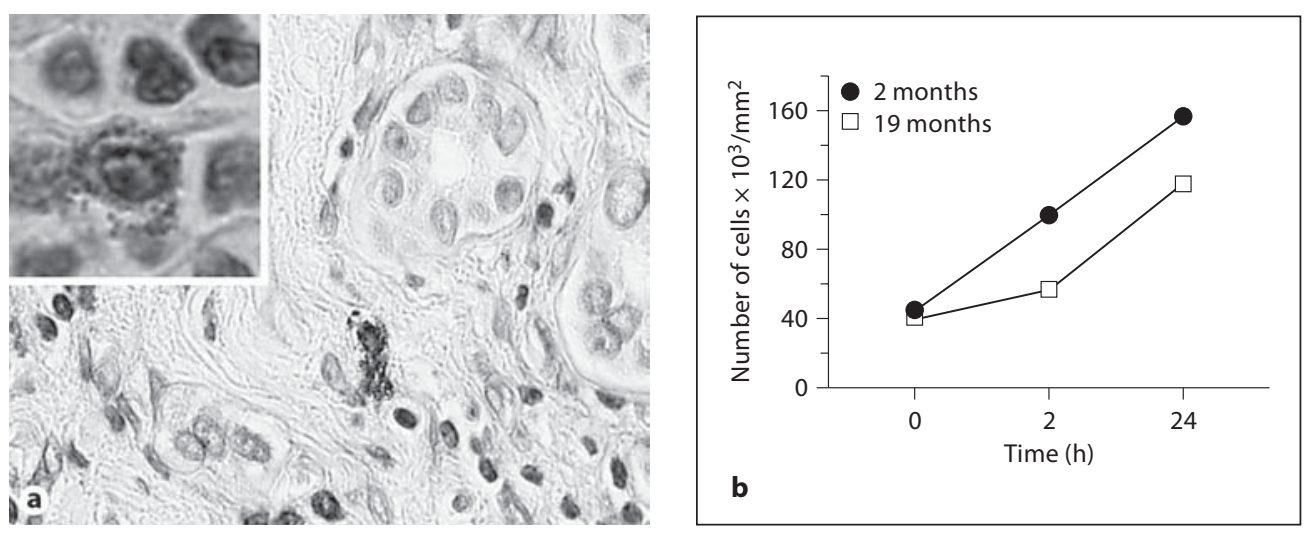

Fig. 3. a Localization of mast cells (MC) in rat liver: MCs are mainly recognizable in the connective tissue near the portal tracts and centrolobular veins. These cells are usually histochemically stained with toluidine blue, which metachromatically stains the glycosaminoglycans of MC granules (toluidine blue, $\times 40$; inset, $\times 100$ ). $\mathbf{b}$ MC densities in rats aged 2 and 19 months, untreated and 2 and $24 \mathrm{~h}$ after $\mathrm{CCl}_{4}$. $\mathrm{MC}$ density was considerably raised in young rats 2 and $24 \mathrm{~h}$ after $\mathrm{CCl}_{4}$ : the difference between untreated rats and treated 2-month-old rats $24 \mathrm{~h}$ after intoxication was significant $(\mathrm{p}<0.0001)$. In the 19 -month-old rats, MC density increased less than in the young rats, but there were significant differences between the untreated rats and the treated rats $2 \mathrm{~h}$ after $\mathrm{CCl}_{4}(\mathrm{p}=0.032)$, and between the densities after 2 and $24 \mathrm{~h}(\mathrm{p}=0.037)$.

of acute inflammation, in order to detect any age-dependent changes of their density in the liver [37, 38].

Histological analysis (fig. 3a) showed that although MCs were mainly located in the connective tissue near the portal tracts and centrolobular veins, there were no real differences between the various zonal arrangements of the hepatic cells and the microcirculatory system. MC density rose considerably in young rats 2 and $24 \mathrm{~h}$ after $\mathrm{CCl}_{4}$ intoxication, whereas this increase was less marked in the old animals. The changes in MC density in rats aged 6 and 12 months fell between those in the rats aged 2 and 19 months (fig. 3b).

These findings, confirming a role for $\mathrm{MC}$ as a marker of acute liver inflammatory reaction, show that there is higher and faster recruitment of these cells in injured tissue in young rats, suggesting that this inflammatory response is lowered during aging.

\section{Conclusions}

These findings point to a basically preserved regenerative response of the aged liver, though somewhat weaker and slower than in younger rats. This was coupled with a reduction in the ability to counteract agents promoting cell necrosis.

From a clinical point of view, these results provide further evidence that: (1) acute liver failure is definitely more severe in old than young subjects; (2) the progression to chronicity and the clinical course of chronic viral hepatitis is worse in aged patients when the infection arises late in life; (3) nevertheless, livers of donors aged $>65$ years, when carefully evaluated, could offer a substantial source of organs, helping satisfy the increasing number of patients listed for liver transplant.

\section{References}

1 Schmucker DL: Aging and the liver: an update. J Gerontol 1998;53:B315-B320.

2 Sakai Y, Zhong R, Garcia B, Zhu L, Wall WJ: Assessment of the longevity of the liver using a rat transplant model. Hepatology 1997;25: 421-425.
Gagliano N, Arosio B, Grizzi F, Masson S, Tagliabue J, Dioguardi N, Vergani C, Annoni G: Reduced collagenolytic activity of metalloproteinases and development of liver fibrosis in the aging rat. Mech Ageing Dev 2002; 123:413-425.
4 Tietz NW, Shuey DF, Wekstein DR: Laboratory values in fit aging individuals sexagenarians through centenarians. Clin Chem 1992;38:1167-1185. 
5 Beyer HS, Sherman R, Zieve L: Aging is associated with reduced liver regeneration and diminished thymidine kinase mRNA content and enzyme activity in the rat. J Lab Clin Med 1991;118:101-108.

-6 Fausto N, Mead JE: Biology of disease. Regulation of liver growth: protooncogenes and transforming growth factors. Lab Invest 1989;60:4-13

7 Michalopulos GK: Liver regeneration: molecular mechanisms of growth control. FASEB J 1990;4:176-187.

8 Pessole Biondo-Simoes ML, Fouto Matias JE, Montibeller GR, Dalledonne Siqueira LC, Da Silva Nunes E, Grassi CA: Effect of aging on liver regeneration in rats. Acta Chir Brasil 2006;21:197-202.

$>9$ Fausto N: Liver regeneration. J Hepatol 2000; 32:19-31.

$>10$ Thompson NL, Mead JE, Braun L, Goyette M, Shank PR, Fausto N: Sequential protooncogene expression during rat liver regeneration. Cancer Res 1986;46:3111-3117.

- 11 Webber EM, Fitzgerald MJ, Brown PI, Bartlett $\mathrm{MH}$, Fausto $\mathrm{N}$ : Transforming growth factor- $\alpha$ expression during liver regeneration after partial hepatectomy and toxic injury, and potential interactions between transforming growth factor- $\alpha$ and hepatocyte growth factor. Hepatology 1993;18: 1422-1431.

- 12 Braun L, Mead JE, Panzica M, Mikumo R, Bell GI, Fausto N: Transforming growth factor- $\beta$ mRNA increases during liver regeneration: a possible paracrine mechanism of growth regulation. Proc Natl Acad Sci USA 1988;85:1539-1543.

$>13$ Gagliano N, Arosio B, Grizzi F, Vergani C, Annoni $\mathrm{G}$ : Acute liver $\mathrm{CCl}_{4}$ intoxication causes low HSP70 gene expression and a delayed transition through the cell cycle in aged rats. Exp Gerontol 2002;37:791-801.

$\checkmark 14$ Stio M, Iantomasi T, Favilli F, Marracchini P, Lunghi B, Vincenzini MT, Treves C: Glutathione metabolism in heart and liver of the aging rat. Biochem Cell Biol 1994;72:58-61.

15 Le Couteur DG, Cogger VC, Markus AMA, Harvey PJ, Yin Z, Ansselin AD, McLean AJ: Pseudocapillarization and associated energy limitation in the aged rat liver. Hepatology 2001;33:537-543.
16 Panduro A, Shalaby F, Shafritz DA: Liverspecific gene expression in various pathophysiologic states. Hepatology 1987;7:10S$18 \mathrm{~S}$.

17 Sorrentino V, Drozdoff V, McKinney MD, Zeitz L, Fleissner E: Potentiation of growth factor activity by exogenous c-myc expression. Proc Natl Acad Sci USA 1986;83:81678171.

18 Karn J, Watson JV, Lowe AD, Green SM, Vedeckis W: Regulation of cell cycle duration by c-myc levels. Oncogene 1989;4:773-787.

19 Smith JR, Pereira-Smith OM: Replicative senescence: implications for in vivo aging and tumor suppression. Science 1996;273:6367.

20 Tomiya T, Ogata I, Fujiwara K: Transforming growth factor- $\alpha$ levels in liver and blood correlate better than hepatocyte growth factor with hepatocyte proliferation during liver regeneration. Am J Pathol 1998;153:955961.

21 Shiota G, Wang TC, Nakamura T, Schmidt EV: Hepatocyte growth factor in transgenic mice: effects on hepatocyte growth, liver regeneration and gene expression. Hepatology 1994;19:962-972.

22 Armendariz-Borunda J, Katai H, Jones M, Seyer JM, Kang AH, Raghow R: Transforming growth factor- $\beta$ gene expression is transiently enhanced at a critical stage during liver regeneration after $\mathrm{CCl}_{4}$ treatment. $\mathrm{Lab}$ Invest 1993;3:283-294.

23 Lindquist S: The heat-shock response. Annu Rev Biochem 1986;55:1151-1191.

24 Fargnoli J, Kunisada T, Fornace AJ, Schneider EL, Holbrook N: Decreased expression of heat shock protein $70 \mathrm{mRNA}$ and protein after heat treatment in cells of aged rats. Proc Natl Acad Sci USA 1990;87:846-850.

25 Heydari AR, Wu B, Takahashi R, Strong R, Richardson A: Expression of heat shock protein 70 is altered by age and diet at the level of transcription. Mol Cell Biol 1993;13: 2909-2918.

26 Wu B, Gu MJ, Heydari AR, Richardson A: The effect of age on the synthesis of two heat shock proteins in the HSP70 family. J Gerontol 1993;48:B50-B56.
27 Zhang HJ, Doctrow SR, Oberley LW, Kregel $\mathrm{KC}$ : Chronic antioxidant enzyme mimetic treatment differentially modulates hyperthermia-induced liver HSP70 expression with aging. J App Physiol 2006;100:13851391.

28 Tracey KJ: The inflammatory reflex. Nature 2002;420:853-859.

29 De Martinis M, Modesti M, Ginaldi L: Phenotype and functional changes of circulating monocytes and polymorphonuclear leucocytes from elderly persons. Immunol Cell Biol 2004;82:415-420.

30 Franceschi C, Bonafe M, Valensin S, Olivieri F, De Luca M, Ottaviani E, De Benedictis G: Inflamm-aging. An evolutionary perspective on immunosenescence. Ann NY Acad Sci 2000;908:244-254.

31 Metcalfe DD, Baram D, Mekori Y: Mast cells. Physiol Rev 1997;77:1033-1079.

32 Okayama Y, Kawakami T: Development, migration, and survival of mast cells. Immunol Res 2006;34:97-115.

33 Gurish MF, Boyce JA: Mast cells: ontogeny, homing, and recruitment of a unique innate effector cell. J Allergy Clin Immunol 2006; 117:1285-1291.

34 Franceschini B, Ceva-Grimaldi G, Russo C Dioguardi N, Grizzi F: The complex functions of mast cells in chronic human liver diseases. Dig Dis Sci 2006;51:2248-2256.

35 Kawakami T, Galli SJ: Regulation of mastcell and basophil function and survival by IgE. Nat Rev Immunol 2002;2:773-786.

36 Nguyen M, Pace AJ, Koller BH: Age-induced reprogramming of mast cell degranulation. J Immunol 2005;175:5701-5707.

37 Grizzi F, Franceschini B, Barbieri B, Gagliano N, Arosio B, Chiriva-Internati M, Annoni G, Dioguardi N: Mast cell density: a quantitative index of acute liver inflammation. Anal Quant Cytol Histol 2002;24:63-69.

38 Grizzi F, Franceschini B, Gagliano N, Moscheni C, Annoni G, Vergani C, Hermonat PL, Chiriva-Internati M, Dioguardi $\mathrm{N}$ : Mast cell density, hepatic stellate cell activation and TGF- $\beta_{1}$ transcripts in the aging Sprague-Dawley rat during early acute liver injury. Toxicol Pathol 2003;31:173-178. 